\title{
Miradas sobre o poder: A nova agência política do movimento negro brasileiro (2004-2021)
}

Views on Power: The New Political Agency of the Brazilian Black Movement (2004-2021)

\author{
Aline Pereira ${ }^{\star}$ \\ Vantuil Pereira ${ }^{* *}$
}

Resumo: $\mathrm{O}$ artigo sustenta que a resistência negra no período pós-abolição passou por inúmeras transformações, somente percebidas pela historiografia a partir de sua renovação quanto aos enfoques e às perspectivas. No que tange à agência negra, notamos uma alteração no quadro das mobilizações sociais, em fins dos anos 1970. A partir do cenário aberto no final dos anos 1990, a luta anterior passa a fazer uso de novas formas de embates antirracistas, sendo a educação superior um dos principais focos de atenção e linha estratégica de atuação, no sentido de superação das desigualdades, percurso finalizado com a implementação das cotas raciais (2004). Isso vem alterando substancialmente a agenda política racial no país, resultando na reconfiguração da agência negra, notada pelo crescente número de
Abstract: The article argues that black resistance in the post-abolition period underwent innumerable transformations, which have only been perceived by historiography since its renewal in terms of focus and perspectives. With regard to black agency, we note a change in the framework of social mobilizations at the end of the 1970s. Starting from the scenario opened at the end of the 1990s, the previous struggle began to make use of new forms of antiracist struggles, with higher education being one of the main focuses of attention and strategic line of action, in the sense of overcoming inequalities; a path that ended with the implementation of racial quotas (2004). This has substantially altered the racial political agenda in the country, resulting in the reconfiguration of black agency,

\footnotetext{
* Universidade do Estado do Rio de Janeiro (UERJ), Rio de Janeiro, RJ, Brasil. alineppereira@yahoo. com.br <https://orcid.org/0000-0002-0942-7444>

** Universidade Federal do Rio de Janeiro (UFRJ), Rio de Janeiro, RJ, Brasil. vantuilpereira@hotmail. com <https://orcid.org/0000-0001-6673-1963>
} 
temas raciais na produção acadêmica, bem como pelo surgimento de um mercado editorial voltado às temáticas raciais. Palavras-chave: Agência negra; Poder negro; Mercado editorial negro; Movimento negro brasileiro. noted by the growing number of racial themes in academic production, as well as the emergence of a publishing market focused on racial themes.

Keywords: Black agency; Black Power; Black Publishing Market; Black Brazilian Movement.

"A grande ilusão vivida, por todo conservador, é que ele será capaz de evitar as inevitáveis mudanças, conjurar as surpresas da vida e da história”

(Albuquerque Jr., 2017, p. 167).

A proposta deste artigo é abordar o surgimento da nova agência negra no Brasil. Fruto de um longo processo que marca a resistência de sujeitos oriundos da diáspora iniciada no século XVI, chegamos à contemporaneidade com perspectivas que demonstram novas correlações de forças resultantes de um forte embate de projetos sociais.

Se, de um lado, temos projetos sustentados em um passado elitista, machista e patriarcal, que, ao longo do tempo, procurou apagar os rastros e as marcas de segmentos subalternizados, tais como os escravizados e as mulheres; do outro assistimos a uma permanente resistência e ressignificação de lutas políticas em torno da afirmação e da vontade de sujeitos históricos que, a partir de lutas abertas ou microrresistências, procuraram imprimir a sua marca no mundo.

Em um certo sentido, a historiografia tem feito parte deste processo, pois, durante muito tempo, ela corroborou com o discurso hegemônico dos segmentos dominantes, passando, nos últimos quarenta anos, por profundas transformações.

As repercussões foram lentas. Entretanto, nem a linearidade, tampouco a teleologia, explicam-nas. No alvorecer mais recente das reflexões em torno das relações raciais, assistimos a muitas idas e vindas, bem como a muitos embates teóricos e políticos, que afetam a distribuição do poder na sociedade e nos espaços acadêmicos (Maio; Santos, 2005). Equivale dizer, por outro lado, que as mo- 
bilizações negras "arrombaram a porta" da historiografia e de outras áreas do conhecimento, como têm apontado os estudos de Gomes e Domingues (2014).

Estes acontecimentos potencializaram um novo enfoque sobre a história das relações raciais nos últimos quinze anos. Uma narrativa (ou história a contrapelo) foi construída pelo movimento de negras/os brasileiras/os que, ao longo de séculos, produziu algo que vai ao encontro do que foi notado por Josep Fontana (1998, p. 275): “cada momento do passado não contém apenas a semente de um futuro predeterminado e inescapável, mas sim a de toda uma diversidade de futuros possíveis, um dos quais pode acabar convertendo-se em dominante".

As cotas raciais são aqui entendidas como frutos da mobilização do movimento negro no cenário pós-Durban ${ }^{1}$, de um ambiente nacional político favorável à gestação de políticas públicas voltadas à juventude negra, à implementação do ensino de história da África e da cultura afro-brasileira e indígena e à ampliação do escopo de atuação do movimento negro, influenciado pela transnacionalização e por uma renovação epistemológica historicamente localizada.

Este artigo é o resultado de investigações que objetivam refletir sobre a emergência de um novo momento das mobilizações negras entre 2004 e 2021 e sobre como se configura o papel e a capacidade das/os negras/os em se organizar. Optamos por analisar os impactos das cotas raciais e as consequentes demandas delas surgidas, em especial a ampliação do mercado editorial de temas raciais. Nesta última parte, embora fosse desejável, não será possível a análise pormenorizada da relação autor, obra e público leitor, considerando-se os limites do texto.

Nossa hipótese de trabalho é a de que o advento das políticas de promoção da igualdade de acesso ao ensino superior, incluindo o seu debate e a sua implementação, revitalizou a ação negra, ampliando as demandas por parte destes segmentos, o que engendrou, inclusive, o surgimento de um mercado editorial voltado exclusivamente para temáticas inerentes à identidade afro-brasileira. Tal ambiente consolidou antigas tendências e criou ênfases às quais podemos denominar nova agência negra.

O trabalho será dividido em três partes. Na primeira parte, faremos uma reflexão teórico-metodologia acerca das condicionantes que sustentam os argumentos desenvolvidos ao longo do trabalho. Na segunda, analisaremos a 
luta travada pelo movimento negro desde o pós-abolição, indicando as características dessa mobilização. Por fim, argumentaremos que, nos últimos quinze anos, o movimento negro entrou em um novo estágio de mobilização e organização. Analisaremos as características deste período, dando ênfase ao advento das cotas raciais no ensino superior, responsáveis pelo debate público e, consequentemente, pelo surgimento de um novo mercado editorial negro, uma das consequências mais visíveis do poder negro em movimento.

A metodologia adotada seguirá, além de revisão bibliográfica concernente ao tema da pesquisa, a análise da produção periódica voltada à temática racial no período compreendido. Além disso, fizemos um levantamento, no período entre 2004 e 2021, das pesquisas que envolvem o assunto na base de teses e dissertações da CAPES.

\section{DESLOCAMENTOS HISTORIOGRÁFICOS}

De acordo com o historiador Josep Fontana (1998, pp. 275-276), é preciso romper com a ideia de uma história linear (única), e recuperarmos as coisas que deixamos esquecidas pelo caminho. $\mathrm{O}$ peso de projetos, racionalidades e culturas que não conseguiram se impor deveriam nos ajudar a escapar, com o enriquecimento de horizontes, "da resignação a quem pretende condenar-nos ao discurso atual". Para o autor basco, "nunca é o fim da história, somente que sempre nos encontramos no fim de uma história e no começo de outra ou de outras cujo curso não podemos predizer".

As visões do passado estão em disputa. Entretanto, cada período histórico revela características próprias que agudizam tendências e colocam em relevo determinados padrões frequentemente ignorados por seus antecessores. Quanto às relações raciais e aos seus temas derivados, tais como escravidão, cidadania, pós-escravidão, mundos do trabalho e negritude, não é mais possível concebê-los distanciados da realidade em que vivemos. Como argumentou Carvalho (2006), estes temas sempre exigem que nos posicionemos.

Durval Albuquerque Jr. apontou as tensões que envolvem o fazer histórico, seu compromisso social e as consequências sociais e políticas do ofício. Argumenta ele que, 
Ao escrever história, o historiador tem que fazer escolhas, tem que definir o lado de quem vai ficar, quais são seus companheiros no passado, de quem vai querer se acompanhar. $\mathrm{O}$ historiador deve escolher de que espectros, de que fantasmas vai se tornar o cavalo, de qual o espírito vai querer ser o médium. O historiador tem que optar por ser o ventríloquo de vozes que jazem caladas sob pilhas de tempos [...]. Em todos esses momentos a política se faz presente [...] (Albuquerque Jr., 2019, pp. 190-191).

Como afirmou Álvaro Pereira do Nascimento (2016, p. 620), é preciso superar a "história em migalhas" na qual nos metemos, ampliando nossa bibliografia, os nossos recortes e as nossas especialidades. O tema das relações raciais, conforme já indicamos, requer uma compreensão ampla.

Assim, a história do tempo presente, ponto de partida de nossa abordagem teórico-metodológica, reivindica ao historiador uma atitude política frente ao vivido. Ele deve se expor ao debate público. Trata-se de uma interpelação do presente que invoca uma abordagem sociocultural para articular as análises das relações sociais e de suas representações (Lohn, 2019, p. 18).

Ricoeur (1994, p. 372) propõe não aceitarmos que o passado seja tomado como acabado, imutável ou irretocável, pois "é preciso reabrir o passado, nele reviver potencialidades não realizadas, contrariadas ou até massacradas". Visto desta maneira, o tempo pretérito é uma tradição viva.

A perspectiva nos conduz para a necessária ruptura da história única e para as potencialidades profícuas de introduzirmos epistemologias alternativas ao enfoque eurocentrado. Um dos ganhos da história do tempo presente diz respeito às possibilidades de diálogos com outros campos de conhecimento. Assim, os estudos pós-coloniais, subalternos e decoloniais se apresentam como frutos do amadurecimento crítico em relação aos caminhos epistemológicos hegemônicos, que invisibilizaram povos submetidos ao domínio Ocidental, deslocando o eixo da narrativa para um novo geoconhecimento (Baltar, 2020, pp. 21-47).

Segundo Mignolo (2008), o pensamento decolonial é uma prática, uma reflexão crítica, bem como um agir politicamente. Ele se alicerça pela desconstrução de discursos e práticas que propugnam a sujeição dos indivíduos, ocorrendo o deslocamento na relação sujeito-objeto.

Como argumentou Figueiredo e Grosfoguel (2007, p. 38), “o ponto central aqui é o lugar da enunciação, isto é, a localização étnica, sexual, racial, de clas- 
se e de gênero do sujeito que enuncia”, impactando nas relações de poder que este deslocamento provoca, e em um novo corpo-política do conhecimento.

A partir das perspectivas acima apontadas, temos novas referências para pensarmos a agência negra, definida por Molefi Asante (2009, p. 93) como a capacidade do ser humano de dispor dos recursos psicológicos e culturais necessários para o avanço da liberdade humana. A agência possui interfaces com as estruturas de poder, as resistências e as probabilidades a eles relacionadas. Agência e poder estão conectados como faces da mesma moeda (Giddens, 2003, pp. 17-19).

Um dos aspectos mais relevantes acerca da ideia e do sentido de agência está relacionado, portanto, à intencionalidade com que os sujeitos sociais agem e produzem ação para transformarem dadas estruturas. Sob este ponto de vista, agência é a capacidade e/ou desejo para transformar que supõe, por outro lado, deter o poder para fazê-lo ou para mobilizar recursos ao seu projeto, seja ele em um período imediato ou ao longo do tempo. Tais elementos estão intrinsecamente ligados, portanto, aos contextos e às conjunturas (Giddens, 2003, p. 13; Otner, 2016). Assim, o agenciamento está envolto nos conflitos e nas micro-resistências, fazendo com que o binômio poder/resistência sejam entidades relacionadas (Tarrow, 2009).

Segundo Sara Mahmood (2019), um dos componentes mais destacados na agência é a sua capacidade de perturbar os discursos dominantes e, ao mesmo tempo, tensionar visando a mudanças. Estas tensões não só agitam o cotidiano como, considerando o contexto, podem levar a alteração na cultura política de uma determinada sociedade.

É sob o signo de novas perspectivas históricas, novos enfoques teórico-metodológicos e de uma apreensão entre agência e poder que podemos entender os caminhos percorridos pelo movimento negro desde o pós-abolição, numa linha de rupturas e continuidades cuja centralidade se situa na luta contra o preconceito, o racismo e as assimetrias deles decorrentes.

\section{O LONGO PROCESSO DE CONSTITUIÇÃO \\ DA AGÊNCIA NEGRA (1890-2004)}

Se, durante muito tempo, à semelhança dos positivistas do século XIX, acreditou-se na inexistência da agência negra, muito recentemente, por força 
de uma nova reconfiguração do movimento negro, pelo mal-estar intelectual vivido em finais dos anos 1970 e - não menos importante - pela influência recebida de autores como E. P. Thompson (1987), passamos a notar que a resistência escrava sempre fizera parte do cotidiano dos homens e das mulheres trazidos de forma violenta em uma diáspora sem parâmetro histórico (Chalhoub, 1986; Gomes; Domingues, 2014; Nascimento, 2016; Abreu, Mattos; Grinberg, 2019).

Com o passar do tempo, essa agência se alterou, tornando-se a luta dos escravizados o ponto de referência no pós-abolição (Gomes, 2005). Assim, jornais e organizações negras, muitos assimilacionistas (Domingues, 2007), foram capazes de apontar o preconceito de cor como um dos entraves para a inserção dos negros na sociedade (Fernandes, 2008).

A partir de 1944, algumas novas organizações e geração intelectual ${ }^{2}$, com origens no recente passado escravista, representadas, sobretudo, por Abdias do Nascimento (2004), Guerreiro Ramos (1995) e Clóvis Moura (1983), formularam concepções originais acerca do conhecimento e do lugar do negro na sociologia e na história. Se Nascimento buscou a valorização social e artística da cultura afro-brasileira, Ramos produziria críticas acerca da nossa importada sociologia, que teria sido responsável por tornar o negro objeto de laboratório, sem pé na vida real, em oposição ao "negro vida". O autor também formulou as primeiras linhas em torno de um conceito de branquitude.

Já Moura foi fundamental ao resgatar as lutas negras desde Palmares e dos movimentos quilombolas, que atravessaram gerações, tornando-nos claro que a luta pré-abolição contara com um protagonismo negro que não se esgotou no sistema escravista.

Simultaneamente às principais formulações destes autores, a ideologia da democracia racial, propagada a partir do pensamento de Gilberto Freyre, justificava um projeto de poder elitista, que escamoteava as tensões do passado escravista, defendendo a hibridização da formação social brasileira. O pensamento do autor pernambucano adocicou as relações entre portugueses, africanos e indígenas, desconsiderando não somente o caráter violento da escravidão, como também enfatizando a mestiçagem, responsável pela disseminação de um valor nacional que silenciava o conflito étnico (Bastos, 2012).

Tal ideologia se tornou o marco da política identitária assumida pela ditadura civil militar implantada em 1964, ocasionando o silenciamento público 
do debate racial, também ocorrendo o refluxo da produção acadêmica e a limitação de funcionamento de jornais voltados ao tema.

Foi somente em finais da década de 1970 que o processo de resistência contra a discriminação, o preconceito e o racismo passaram a se fortalecer com o surgimento do Movimento Negro Unificado (MNU), constituindo-se o denominado movimento negro contemporâneo (Pereira, 2013).

O MNU teria sido fruto do contexto de ebulição social que envolveu o surgimento de diversos outros atores, que desfechou uma luta contra a ditadura e pela democratização do país. Assim, o movimento negro contemporâneo atravessaria as décadas seguintes com muitas transformações em sua conformação, ora recusando se aproximar da institucionalidade (Leitão; Silva, 2017), ora fazendo crer em uma dicotomia política/cultura e secundarizando a luta das mulheres negras (Pereira, 2013).

Tais disputas e contrações não impediram a participação desses movimentos, tanto na promoção de políticas de promoção da igualdade, como ocorrido no estado de São Paulo, quanto nas mobilizações em torno da Assembleia Constituinte de 1987-88, resultando na aproximação destas organizações com lideranças negras eleitas em partidos como PC do B, PT e PDT.

Entretanto, como todos os demais movimentos sociais do período compreendido entre 1980 e 2000, ele sofreu os reveses influenciados pela conjuntura nacional e internacional. A imposição da agenda neoliberal, implantada no país a partir de 1991, enfraqueceu o Estado em temas sociais, impactando diretamente nas vidas negras (Domingues, 2008; Dagnino, 1994). Tal processo teria sido responsável pela ampliação do número de Organizações Não Governamentais (ONGs), muitas relacionadas ao tema racial, sobretudo organizações de mulheres negras, tais como Geledés, Fala Preta!, Organização de Mulheres Negras e Crioula (Santos, 2009b). Outro elemento constitutivo do período diz respeito ao crescente processo de transnacionalização do movimento negro, que, como veremos, desempenharia papel-chave no transcurso dos acontecimentos pós-Durban.

Em 1995, ocorreu outro momento de inflexão política para o movimento negro. Nas comemorações dos 300 anos da morte de Zumbi dos Palmares, as organizações promoveram a Marcha Zumbi, exigindo que o Estado brasileiro assumisse compromissos na promoção de ações antirracistas, resultando na 
criação do grupo de trabalho interministerial, coordenado pela Secretaria Especial de Direitos Humanos.

A criação deste grupo vinha ao encontro de estudos promovidos por Hasenbalg (1979), que demonstraram ser o racismo não uma fantasia dos negros brasileiros, mas um mecanismo de favorecimento dos brancos e, diferentemente de Florestan Fernandes (2008), indicava que a persistência das assimetrias raciais e sociais não tinha relação direta com o passado escravista. Para Hasenbalg, o racismo brasileiro se metamorfoseou a partir da industrialização (modernização), se tornando um elemento que se somava ao passado brasileiro. O resultado disto podia ser observado nas condições de vida, na ocupação subordinada de postos de trabalho e na dificuldade de acesso e permanência na educação, ocasionando desigualdades cumulativas.

Tais resultados também se aproximavam das constatações promovidas por autoras negras como Beatriz Nascimento (2018), Lélia Gonzalez (1988) e Neusa Santos Souza (1990), que traduziram as dimensões históricas e de gênero, cultura e psiquiatria, como partes relacionadas ao apagamento da história do negro brasileiro. Todavia, Petrônio Domingues (2007) notou que, embora o ambiente das décadas de 1970-1990 tivesse facilitado a agenda política social, ele também foi responsável pelo refluxo das mobilizações, similar ao que ocorreu com outros movimentos sociais (Doimo, 1995).

A nova etapa foi causada pelo ambiente internacional pós-Durban e pela ascensão do Partido dos Trabalhadores ao governo, em 2003, ocasionando a criação da Secretaria de Promoção da Igualdade Racial (SEPPIR). Neste contexto, alguns estados da federação consideraram a adoção de ações afirmativas em suas instituições de ensino, sendo implantadas, ainda em 2003, as primeiras cotas raciais na Universidade do Estado do Rio de Janeiro e na Universidade do Estado da Bahia. Tal política também contou com o protagonismo da Universidade de Brasília (UnB) que, no âmbito das instituições de ensino federal, inovou ao admitir alunos pretos e pardos através de políticas de discriminação positiva, a partir de 2004.

O resultado desse processo foi o desencadeamento de um longo debate político e intelectual que mobilizaria tanto setores do movimento negro, favoráveis às políticas adotadas pela UERJ, UNEB e UnB, como grupos que detratariam a proposta, argumentando uma possível cisão racial no país (Maio; Santos, 2005). 
Se há muito o movimento negro vislumbrava o campo da educação como estratégico para a superação do racismo e das assimetrias sociais, a admissão de cotas tornava-se a nova agenda política de mobilização, fazendo ressurgir uma unificação dos movimentos sociais negros em torno do tema (Campos, 2011).

A perspectiva da adoção das cotas raciais abriu um imenso campo de possibilidades (Telles, 2003) que, somando-se ao conjunto de ações combinadas - tais como a alteração na forma de seleção dos estudantes, por meio do Exame Nacional do Ensino Médio (ENEM), pela adoção do Sistema de Seleção Unificada (SISU), pelo Programa Universidade para Todos (PROUNI) e pelo Plano de Reestruturação e Expansão das Universidades Federais (REUNI) -, fez com que houvesse uma mudança sem precedentes no sistema educacional brasileiro.

O que se quer ressaltar aqui é justamente o imbricamento entre as mobilizações promovidas pelo movimento negro e a admissão, por parte da institucionalidade, da necessidade de políticas públicas voltadas à população negra. Sob este prisma, o conflituoso processo iniciado em 1978 criara um ambiente propício para que, no início dos anos 2000, houvesse uma mudança sem precedentes não somente na mobilização política dos negros brasileiros, como também na incorporação de segmentos sociais antes fora dos espaços institucionalizados.

No presente momento, assistimos a um novo episódio da mobilização negra, que comporta um conjunto de transformações que transcendem o próprio campo negro. Estão em disputa novas configurações de reparações históricas, redistribuição de poder, conflitos pela hegemonia e novas configurações socioeconômicas (Artes, 2018).

\section{O LIMIAR DE UM NOVO TEMPO: A NOVA AGÊNCIA NEGRA (2004-2021)}

Embora a luta antirracista venha se dando em diversas frentes, influenciada pela agenda transnacional - por meio de acontecimentos como o \#BlackLivesMatter ${ }^{3}$ e das intensas trocas e articulações do movimento negro brasileiro com organizações latino-americanas e africanas (Igreja; Agudelo, 2014) -, a adoção das ações afirmativas, os seus debates e as suas repercussões alteraram a forma de atuação do movimento negro, impactando a produção do conhecimento relacionado ao tema das relações raciais, bem como despertando o 
interesse editorial pelo assunto. No seu conjunto, tais elementos configuram-se como parte de uma nova agência negra.

Comentando essas transformações ocasionadas pela adoção das cotas raciais, Carvalho (2006, p. 4) argumentou que o debate supracitado praticamente conduziu a um processo de democratização do ensino público (Santos, 2009a). Diríamos mais: ele acenou para uma nova forma de manifestação e de capacidade de atuação dos negros no Brasil.

Face ao conjunto de transformações iniciadas com o advento da Conferência de Durban, Petrônio Domingues (2008) fez um mapeamento das tendências e dos desafios colocados para o conjunto do movimento negro. Conforme reconheceu o autor, não se tratava de uma ruptura. Mesmo porque, segundo Fredric Jameson (2006, p. 41), rupturas não envolvem, necessariamente, mudança de conteúdo: o que frequentemente ocorre é a reestruturação de certos elementos já dados, pois, segundo o autor, "aspectos que em um período ou sistema anterior eram subordinados agora se tornam dominantes".

Parte do que se materializou nada mais é, consideramos, do que a reconfiguração da agência negra, a partir da capacidade de agir por si, intencionalmente visando transformações estruturais. Todavia, ainda que exista uma tradição de luta, não podemos estabelecer uma linha direta que nos leva a crer em uma relação de causa e efeito entre as mobilizações iniciadas em 1978 e as consequentes políticas de ações afirmativas de 2004 (Trapp; Silva, 2012). Como expusemos anteriormente, o próprio movimento negro sofreu com as alterações conjunturais, assim como as influenciou.

Alguns exemplos bastam para desconstruirmos tais ideias. Primeiramente, deve-se notar a existência de uma falsa dicotomia entre cultura e política, as quais sempre estiveram justapostas, sobretudo se tomarmos como referência a persistente tentativa de apagamento da memória negra e o conflito que ela provoca (Borelli; Aboboreira, 2011, p. 165). A mesma descontinuidade encontramos na proposta das cotas raciais. Primeiramente apresentada pelo então senador Abdias do Nascimento, em 1983, tal política apenas se concretizou vinte anos depois.

Como demonstrado, somente quando o ambiente político permitiu é que as primeiras ações passaram a ser implementadas. Escapa à lógica do movimento negro esta temporalidade, ainda que ele buscasse permanentemente influenciar os rumos políticos. São processos que dizem respeito à correlação 
de forças políticas. Dito de outra maneira, trata-se de relações de poder, de poder político (Poulantzas, 1985).

Retomando as reflexões acima iniciadas, notamos que novas dimensões devam ser incorporadas, nos levando a afirmar que, a partir de 2004, uma nova etapa da questão racial se iniciou. Ainda está por ser elaborada uma análise mais detida sobre as características desse período. Podemos, assim, resumi-las:

a) Uma nova leitura sobre a dicotomia política/cultura. A perspectiva identitária tornou-se um instrumento de luta política. Falar de identidade negra, e da questão racial a partir da identidade, é uma arma e uma atitude que mobiliza a política, a qual se soma à demanda por representatividade de sujeitos negros nos espaços sociais.

b) Outra característica diz respeito à capacidade de formulação do movimento negro. Ainda que, nos períodos anteriores, observemos propostas visando a superação do racismo, lhes faltava um conjunto numeroso de intelectuais capaz de formular uma nova cultura política (Figueiredo; Grosfoguel, 2007). Assim, diferentemente do que notou Hanchard (2001), a hegemonia branca tem sido posta em questão. $\mathrm{O}$ ataque ao pensamento da branquitude, a reivindicação de ampliação das políticas de acesso e permanência no ensino superior, combinados com a defesa de cotas no setor privado, em eventos de moda, na televisão, e com as contínuas manifestações em combate às situações que envolvem a violência policial e a necropolítica em curso contra a juventude negra - todos esses eventos com ampla articulação em rede dos diversos tipos de movimento social -, demonstram uma renovação da capacidade de intervenção.

c) A ocupação mais substantiva do espaço institucional. Observamos que a tensão entre o ativismo negro e a participação no campo sempre se colocou historicamente. Entretanto, a legislação antirracista materializada nos últimos anos vem demonstrar que a arena institucional possui um papel central para incorporar amplas parcelas da população no desenvolvimento de políticas públicas que possam redistribuir recursos, partilhar poder e, sobretudo, democratizar a sociedade. Por outro lado, a institucionalização de setores do movimento negro reconfigurou o próprio entendimento do aparelho estatal sobre a questão racial. Nota-se, por exemplo, o papel decisivo ocupado pelos mili- 
tantes negros, na SEPPIR e em secretarias estaduais e municipais de promoção da igualdade racial.

d) A amplitude e o fortalecimento do protagonismo das mulheres negras não ocorre apenas na ação política, mas também no campo intelectual - protagonismo iniciado por Lélia Gonzalez e que hoje conta com inúmeras mulheres que, consequentemente, têm produzido uma renovação não só no campo racial, como também no campo do feminismo.

e) A universidade vem crescentemente ocupando centralidade na luta identitária, na criação de uma cultura política, na reconfiguração do debate em torno do projeto de nação, a partir de uma rediscussão sobre o pensamento social e o lugar ocupado pela questão racial nos impasses políticos nacionais. Sob este enfoque, a desconfiança nutrida pela militância negra cede lugar ao diálogo entre os campos intelectuais e da atuação política. Entretanto, é no ambiente acadêmico que notamos as resistências mais profundas, no sentido de se ampliarem as políticas de promoção da igualdade racial. Observe-se, por exemplo, a morosidade na aplicação de cotas para negros nos concursos docentes e as dificuldades de implementação de políticas de ações afirmativas para a recepção de pós-graduandos.

Apesar destas dificuldades, verificamos que, desde 2004, a produção acadêmica voltada à questão racial tem crescido abundantemente. Deste modo, a partir da primeira geração de jovens pós-cotas, recém-saídos da graduação, observamos o crescimento quase exponencial da produção de teses e dissertações sobre o assunto. As pesquisas mostram a vivacidade temática que invade a academia, sendo fortalecida pela crescente expansão de núcleos de estudos afro-brasileiros, pela realização de congressos organizados pela Associação Brasileira de Pesquisadores/as Negros/as, pela ampliação de grupos de pesquisa e pelo surgimento de coletivos de discentes e de docentes negras e negros (Guimarães; Sotero; Rios, 2020).

No quadro abaixo, demonstramos o crescimento vertiginoso de teses e dissertações voltadas às temáticas raciais, apontadas no portal CAPES. 


\begin{tabular}{|l|c|c|c|c|c|}
\hline & $1997-2001$ & $2002-2006$ & $2007-2011$ & $2012-2016$ & $2017-2021$ \\
\hline Raça & 1390 & 2401 & 3155 & 4589 & 3851 \\
\hline Racismo & 105 & 217 & 467 & 785 & 1259 \\
\hline Relações raciais & 51 & 110 & 181 & 234 & 264 \\
\hline Mulher negra & 16 & 37 & 78 & 134 & 197 \\
\hline Cultura negra & 23 & 37 & 77 & 106 & 125 \\
\hline Quilombola & 8 & 36 & 228 & 704 & 771 \\
\hline Pós-colonial & 18 & 57 & 113 & 248 & 239 \\
\hline $\begin{array}{l}\text { Feminismo } \\
\text { negro }\end{array}$ & 590 & 995 & 1616 & 2497 & 2728 \\
\hline África & 228 & 449 & 845 & 1457 & 1204 \\
\hline Fanon & 5 & 3 & 26 & 98 & 144 \\
\hline $\begin{array}{l}\text { História da } \\
\text { África }\end{array}$ & 1 & 8 & 27 & 103 & 103 \\
\hline Favela & 131 & 256 & 318 & 493 & 350 \\
\hline Quilombo & 29 & 65 & 201 & 574 & 479 \\
\hline $\begin{array}{l}\text { Comunidades } \\
\text { Tradicionais }\end{array}$ & 27 & 87 & 262 & 564 & 577 \\
\hline
\end{tabular}

Fonte: Portal CAPES (Catálogo de Teses e Dissertações)

Embora parte desse crescimento se deva ao surgimento de novos programas de pós-graduação, entre 2010 e 2020, este aumento não explica por si o interesse pelo tema racial. Mesmo porque grande parte dessa inflação esteve relacionada às áreas de ciências exatas e da terra e a programas multidisciplinares (Lopes, 2019, p. 9).

Em diversas áreas do conhecimento, os temas raciais conheceram crescimento vertiginoso, desconcentrando as pesquisas que até então vinham sendo desenvolvidas em áreas como a sociologia, a antropologia e a história. Áreas como a educação, a psicologia, a saúde, a economia, dentre outras, passaram a figurar como campos de estudos que recepcionam as temáticas raciais.

f) Observa-se a renovação epistemológica: a partir do questionamento da relação sujeito-objeto, os intelectuais passam a falar de si e da sua experiência como negras/os. Nota-se a utilização de novos quadros de referência, tais como os estudos culturais e subalternos, o pós-colonialismo e a afrocentricidade. Desloca-se o sentido de se produzir conhecimento que, colocado nas mãos dos 
que vivem e experimentam as assimetrias raciais, revela os mecanismos de funcionamento do racismo em nosso país.

g) Ganham evidências nesses estudos temáticas como as do corpo negro, do feminismo negro, da violência contra a mulher negra, da sexualidade, da biopolítica, da necropolítica e do genocídio contra a juventude negra. Temas como favela, segurança e cidade recebem novos prismas cuja centralidade passa a ser a sobrevivência, a relação entre este espaço geográfico e a violência cotidiana, mas também relatam a resistência e as formas de se conceberem alternativas à falta de serviços públicos.

f) Uma crescente conexão entre o movimento negro brasileiro e outras lutas transnacionais, caracterizada pelas repercussões de casos envolvendo racismo, tanto nos Estados Unidos quanto em outras partes do globo.

A última característica pode ser notada com o advento de novas produções editoriais, cujos temas se relacionam com a questão racial, condizentes com o que veremos a seguir.

\section{UM NOVO CENÁRIO EDITORIAL NEGRO}

A presença dos negros na sociedade brasileira, quando não ocultada e desqualificada, foi também inviabilizada pelas estruturas de poder vigentes durante muitos anos. O mercado editorial esteve atrelado a esse processo, considerando que é um ente que também faz escolhas comerciais, mas, sobretudo, políticas, para garantir a publicação dos títulos que estarão a correr nas prensas, sendo expostos nas vitrines das principais livrarias, e, consequentemente, circulando nas casas do público leitor.

Exemplo está na recepção tardia aos escritores negros, principalmente os de origem não europeia, publicados no Brasil. Por muitos anos, era praticamente impossível se ter acesso às obras de autores negros estrangeiros em língua portuguesa. Mas, tal situação, como podemos constatar, começou a mudar especialmente nas duas últimas décadas. Hoje, ao acessar uma livraria na cidade do Rio de Janeiro, por exemplo, é facilmente perceptível a transformação no que nos é ofertado nas prateleiras. Além das escritoras nigerianas Chimamanda Ngozi Adichie e Buchi Emecheta, atualmente temos os títulos de Scholastique Mukasonga (Ruanda); Paulina Chiziane (Moçambique); Grada Kilomba (portuguesa, mas com origens em Angola e São Tomé e Príncipe); 
Angela Davis, bell hooks, Patricia Hill Collins, Maya Angelou, W. E. B. Du Bois, e a reedição de diversas obras de Toni Morrison e James Baldwin (todos os últimos norte-americanos), entre muitos outros. É importante mencionar, ainda, que, nesse contexto, temos a possibilidade de acessar, em nossa língua materna, a produção de Chinua Achebe (Nigéria), Achille Mbembe (Camarões), Aimé Césaire e Frantz Fanon (os dois últimos da Martinica).

Citemos o caso de Grada Kilomba (2019), autora de Memórias da plantação: episódios de racismo cotidiano, originalmente publicado em língua inglesa em 2008, quando lançado na Alemanha. Somente onze anos depois, a obra acima, a primeira escrita pela psicanalista e artista interdisciplinar, teve sua edição traduzida em português, simultaneamente no Brasil e em Portugal. Sobre o hiato entre a publicação original e a tradução, a autora afirma, logo nas páginas iniciais do livro, que a circulação desse tipo de literatura esteve, de certa forma, impedida, tanto na antiga metrópole quanto na ex-colônia lusitana, porque "os comuns gloriosos e românticos discursos do passado colonial, com os fortes acentos patriarcais, não o permitiram” (Kilomba, 2019, p. 13).

Outro caso bastante significativo é o de Aimé Césaire, autor de Diário de retorno ao país natal, cuja publicação original francesa data de 1939, sendo publicada no Brasil em português somente em 2012 (cf. Césaire, 2012). Naquela publicação, o autor, pela primeira vez, fez uso do conceito de negritude. Discurso sobre colonialismo, também de Césaire, foi originalmente publicado na França na década de 1950. Em 2020, a Editora Veneta o publicou em português brasileiro (cf. Césaire, 2020).

Sobre o mesmo assunto, Antônio Sergio Guimarães discorreu a respeito da demorada recepção, no Brasil, do pensamento de Frantz Fanon. Um de seus primeiros escritos, Pele negra, máscaras brancas, foi publicado na França em 1952 e logo alcançou respeitável repercussão em outros países, sobretudo após as críticas elogiosas e o prefácio de Jean Paul Sartre. Embora já circulasse com discrição aqui no país, dada a conjuntura de recrudescimento do cenário político pelo golpe empresarial-militar de 1964, somente em 1983 a dita obra ganhou publicação na nossa língua materna.

Considerando a nossa abordagem, cabe ainda citarmos a declaração do historiador brasilianista George Reid Andrews, que, ao tentar publicar Negros e brancos em São Paulo - 1888-1988 (1998) nestas bandas do Atlântico, foi desencorajado pelos editores: 
No caso específico deste livro, me informaram as editoras com as quais falei (e falei com muitas), os obstáculos foram maiores ainda. "Qualquer livro sobre negros não vai ter mercado", asseguraram-me. "Salvo intelectuais, ninguém quer saber deste tema. Desculpe a nossa franqueza, mas o seu livro é simplesmente ineditável no Brasil” (Andrews, 1998).

A obra foi acolhida somente em 1998, por uma editora universitária, ligada a uma instituição privada, mais antenada às novas pesquisas que pulsavam sobre o assunto no ambiente acadêmico.

Consideramos importante apontar que a tradução, em língua portuguesa, de outros nomes internacionais caros às questões de gênero, de raça e de identidade, começou a ocorrer com força no Brasil a partir da década de 2010. Alguns exemplos: Angela Davis - Mulheres, raça e classe (2016); Mulheres, cultura e política (2017); A liberdade é uma luta constante (2018) e Patricia Hill Collins - Pensamento feminista negro (2019).

Da mesma maneira, o acesso à parte da produção intelectual de bell hooks em língua portuguesa também se deu a partir do crescente interesse por temáticas que envolvem a mulher e o feminismo negro, o racismo e as demandas por representatividade. Exemplos de suas obras aqui traduzidas são: Ensinando a transgredir: a educação como prática da liberdade (2013); O feminismo é para todo mundo: políticas arrebatadoras (2018); Teoria feminista: da Margem ao Centro (2019); Olhares negros: raça e representação (2019). Houve ainda o acesso à produção de Maya Angelou - Mamãe \& Eu \& Mamãe (2018); Eu sei por que o pássaro canta na gaiola (2018) - e à de Audre Lorde - Irmã Outsider: Ensaios e Conferências (2019).

Se os homens fazem as escolhas a partir de posicionamentos políticos, e se o mercado editorial está atento às demandas instadas pela sociedade, é fato que as políticas de ações afirmativas e as suas consequências podem ter influído diretamente no aumento da publicação das obras acima indicadas em língua portuguesa. As influências africanas no Brasil precisam ser contextualizadas às demandas por representatividade e ao interesse ampliado do debate acadêmico por parte de um novo grupo de jovens que reivindica seu espaço e lugar no mundo.

Conforme estamos argumentando, tal interesse nesse tipo de obra especializada e temática está diretamente relacionado à ascensão verificada, nos últimos anos, de jovens negros e negras ao ensino superior, ampliado quando 
notamos, também, a chegada de docentes negros/as às Universidades, com a instituição da Lei 12.990/2014, que reserva 20\% das vagas para candidatos/as negros/as no âmbito da administração pública federal.

Soma-se a este quadro o impulso dado pela publicação da portaria do Ministério da Educação, de maio de 2016, que induziu a adoção de cotas raciais nos programas de pós-graduação. Um estudo dirigido por Amélia Artes (2018, p. 14) tem indicado alterações qualitativas na presença de estudantes negras/ os na pós-graduação, desde 2010.

Embora os dados apresentados se refiram a período anterior ao incentivo instituído pelo Ministério da Educação, eles são corroborados pelas análises apresentadas por Anna Venturini e João Feres Jr. (2020), que apontaram um crescimento vertiginoso da adoção de cotas raciais nos programas de pósgraduação desde 2016. Nota-se ainda um aumento do número de teses e dissertações que têm por foco a temática racial (Artes; Ricoldi, 2015; Mattos; Santos; Mattos, 2020).

Em conjunto, esses estudos indicam preocupações relacionadas aos aspectos verticais e horizontais da aplicação das citadas políticas, mantendo-se distanciamentos entre negros e brancos, tanto na graduação quanto na pós-graduação. Contudo, eles não desconhecem o aumento significativo no número de ingressos de estudantes negros nos dois estágios de formação.

Acreditamos em uma tendência do aumento da produção discente, visto que a adoção de cotas na pós-graduação somente chegará aos seus primeiros grandes resultados a partir de 2021. Tudo isso deve ser articulado com o interesse editorial às reivindicações identitárias desse grupo, que hoje circula mais facilmente por lugares até então considerados inacessíveis à parcela marginalizada da população.

Retomando o ponto aqui analisado, é interessante retornar a Antônio Sergio Guimarães (2008, p. 114) e às suas impressões sobre a adoção de Fanon no Brasil como um referencial teórico necessário ao debate sobre gênero, raça e violência política. Se hoje o pensamento do autor martinicano é mais discutido nas universidades, no entanto, conforme as palavras do sociólogo, "ainda estamos engatinhando" no conhecimento da obra do psicanalista, a qual também muito contribuiu para o debate a respeito das lutas anticoloniais que tanto nos dizem sobre as injustiças que permanecem no tempo presente.

Uma das possibilidades apontadas por Antônio Guimarães para que essa 
apropriação da obra de Fanon acontecesse de forma tão lenta estava na "pouca presença de negros nas universidades brasileiras e na consequente escassez teórica sobre as identidades raciais". O autor continua: "a entrada gradual, mas constante, de negros nas nossas universidades de pesquisa poderá abrir, quem sabe, uma larga avenida para os estudos fanonianos" (Guimarães, 2008, p. 114).

Notamos a acertada percepção do autor, visto que o mercado editorial está atento às demandas instadas pelos estudantes que ascenderam ao ensino superior e à pós-graduação, bem como às temáticas que pulsam no ambiente acadêmico e ultrapassam os muros da universidade, que não é um ente isolado da realidade e dos debates. Com a chegada de um corpo discente mais plural do ponto de vista étnico/racial, e com outro recorte econômico social, foi possível ampliar a circularidade das discussões teóricas para além do eixo europeu ou norte-americano. Assim, ganhamos todos nós com a diversidade de temas, autores e publicações necessários à leitura e ao debate no Brasil contemporâneo. Embora já tenhamos caminhado bastante, muitas são as permanências de três séculos de dominação colonial. É contra elas que nos insurgimos, clamando por uma sociedade que não siga reproduzindo e/ou naturalizando as desigualdades socioeconômicas, jurídicas e políticas no país a partir da perspectiva racial.

\section{Conclusẽo}

Neste artigo, procuramos evidenciar um conjunto de transformações relacionadas à agência negra em curso nos últimos quinze anos. Trata-se de uma história que vem a completar o longo período de oralidade e de tradições de resistência negra que, a partir do pós-abolição, ganhou páginas de jornais, organizações políticas, formulações intelectuais e, finalmente, um novo tipo de organização social, surgida no final dos anos 1970.

A historiografia não ficou indiferente a esse processo. Ela passou por transformações, tanto nas abordagens quanto no seu posicionamento teórico-metodológico, representada pela história do tempo presente que, ao tomar como ponto de partida a perspectiva decolonial ou pós-colonial, evidencia uma nova relação sujeito-objeto. Sob estas inspirações, os argumentos aqui apresentados apontaram diversas características que se confirmaram e inovaram, tais como o aumento da participação de discentes negras/os, tanto na graduação 
quanto na pós-graduação, assim como a nova reconfiguração do movimento negro que, depois do advento das cotas, fez aumentar a demanda por estudos das relações raciais, impactando no processo de produção editorial.

Conforme argumentou Costa Douzinas (2011, p. 10), "políticas adequadas surgem apenas quando uma parte excluída demanda ser inclusa e deve mudar as regras de inclusão para conseguir isto". Quando esses grupos tiverem sucesso, um novo sujeito político é constituído "e uma divisão é posta no 'senso comum"” sobre o que é dado, sobre o contexto no qual nós vemos algo como dado.

Como resultado, temos um conjunto de alterações que apontam para novos padrões nas relações de poder no Brasil contemporâneo. Conforme a epígrafe deste trabalho, trata-se de um caminho sem retorno no sentido de que as ações dos atores políticos não podem voltar ao ponto de indiferença e de paralisia. Partindo da sugestão de Norberto Bobbio (2004), pode-se dizer que o referido cenário aponta para "zonas de luz", cujos desdobramentos resultam em revoluções gradativas (Testa, 1995). Todavia, as resistências de segmentos historicamente beneficiados pelo racismo em nosso país podem retardar o processo histórico em curso.

O grande desafio que se coloca no presente momento é, em primeiro lugar, de compreender as nuances deste novo poder negro e, em segundo lugar, de entender como os pontos acima mencionados se articulam.

Para tanto, será preciso esmiuçarmos cada um dos elementos que apontamos em nossos argumentos. Precisamos aprofundar o significado do que seja este poder e, mais ainda, entender como o mercado editorial se amplia para além de questões mercantis; qual o público consumidor dessas obras; quem são esses editores; quais as suas relações com o movimento negro e com o histórico processo de afirmação da identidade e, finalmente, qual o impacto político dessas publicações para a ampliação de um público negro escritor/leitor.

\section{REFERENNCIAS}

ABREU, Martha; MATTOS, Hebe; GRINBERG, Keila. História pública, ensino de história e educação antirracista. Revista História Hoje, v. 8, n. 15, pp. 17-38, 2019. ALBUQUERQUE JR., Durval Muniz de. Uma escola sem sentido: por que a profissão de historiador não é regulamentada? História Unisinos, v. 21, n. 2, pp. 159-168, 2017. 
ALBUQUERQUE JR., Durval Muniz de. História e política, ou a arte de fazer escolhas. Estudos Ibero-Americanos, Porto Alegre, v. 45, n. 3, pp. 186-191, 2019.

ANDREWS, George Reid. Negros e brancos em São Paulo (1888-1988). São Paulo: EDUSC, 1998.

ANGELOU, Maya. Eu sei por que o pássaro canta na gaiola. São Paulo: Astral Cultural, 2018.

ANGELOU, Maya. Mamãe \& Eu \& Mamãe. Rio de Janeiro: Rosa dos Tempos, 2018.

ARTES, Amélia. Dimensionando as desigualdades por sexo e cor/raça na pós-graduação brasileira. Educação em Revista [online], Belo Horizonte, v. 34, pp. 1-23, 2018.

ARTES, Amélia Cristina Abreu; RICOLDI, Arlene Martinez. Acesso de negros no ensino superior: o que mudou entre 2000 e 2010. Cadernos de Pesquisa, São Paulo, v. 45, pp. 858-881, 2015.

BALTAR, Paula. A Teoria Crítica sob o olhar da decolonialidade. Tensões Mundiais, Fortaleza, v. 16, n. 31, pp. 21-47, 2020.

BASTOS, Elide Rugai. Gilberto Freyre e seu tempo: contexto intelectual e questões da época. Sinais Sociais, v. 7, n. 19, pp. 60-87, 2012.

BOBBIO, Norberto. A era dos direitos. Rio de Janeiro: Elsevier, 2004.

BORELLI, Silvia Helena Simões; ABOBOREIRA, Ariane. Teorias/metodologias: trajetos de investigação com coletivos juvenis em São Paulo/Brasil. Revista Latinoamericana de Ciencias Sociales, Niñez y Juventud, v. 9, n. 1, pp. 161-172, 2011.

CAMPOS, Andrelino. As particularidades da escala de ação do movimento negro: algumas considerações sobre a formação do sujeito. Revista Geografares, n. 9, pp. 29-48, 2011.

CARVALHO, José Jorge de. A luta anti-racista dos acadêmicos deve começar no mundo acadêmico. Série Antropologia, v. 394, pp. 1-14, 2006.

CATÁLOGO DE TESES E DISSERTAÇÕES. Disponível em: https://catalogodeteses. capes.gov.br/catalogo-teses/\#!/. Acesso em: 2 mai. 2021.

CÉSAIRE, Aimé. Diário de retorno ao país natal. Tradução, posfácio e notas de Liliam Pestre de Almeida. São Paulo: Edusp, 2012.

CÉSAIRE, Aimé. Discurso sobre o colonialismo. São Paulo: Veneta, 2020.

CHALHOUB, Sidney. Trabalho, lar e botequim. São Paulo: Brasiliense, 1986.

COLLINS, Patricia Hill. Pensamento Feminista Negro: conhecimento, consciência e a política do empoderamento. São Paulo: Boitempo Editorial, 2019.

DAGNINO, Evelina (Org.). Anos 90: política e sociedade no Brasil. São Paulo: Brasiliense, 1994.

DAVIS, Angela. A liberdade é uma luta constante. São Paulo: Boitempo, 2018.

DAVIS, Angela. Mulheres, cultura e política. São Paulo: Boitempo, 2017.

DAVIS, Angela. Mulheres, raça e classe. São Paulo: Boitempo, 2016.

DOIMO, Ana Maria. A vez e a voz do popular: movimentos sociais e participação política no Brasil pós-70. Rio de Janeiro: Relume Dumará: ANPOCS, 1995. 
DOMINGUES, Petrônio. Movimento negro brasileiro: alguns apontamentos históricos. Tempo [online], v. 12, n. 23, pp. 100-122, 2007.

DOMINGUES, Petrônio. Movimento negro brasileiro: história, tendências e dilemas contemporâneos. Dimensões, n. 21, pp. 101-124, 2008.

DOUZINAS, Costas. Os paradoxos dos direitos humanos. Tradução de Caius Brandão. Anuário do Núcleo Interdisciplinar de Estudos e Pesquisas em Direitos Humanos, v. 1, n. 1, 2011.

FERNANDES, Florestan. A integração do negro na sociedade de classes. São Paulo: Editora Globo, 2008.

FIGUEIREDO, Angela; GROSFOGUEL, Ramón. Por que não Guerreiro Ramos? Novos desafios a serem enfrentados pelas universidades públicas brasileiras. Ciência e Cultura, v. 59, n. 2, pp. 36-41, 2007.

GIDDENS, Anthony. A constituição da sociedade. Tradução de Álvaro Cabral. São Paulo: Martins Fontes, 2003.

GOMES, Flávio dos Santos; DOMINGUES, Petrônio. Políticas da raça: experiências e legados da abolição e da pós-emancipação no Brasil. São Paulo: Selo Negro Edições, 2014.

GOMES, Flávio. Negros e Política (1888-1937). Rio de Janeiro: Jorge Zahar, 2005.

GONZALEZ, Lélia. A categoria político-cultural de amefricanidade. Tempo Brasileiro, Rio de Janeiro, n. 92-93, pp. 69-82, 1988.

GUIMARÃES Antonio Sérgio A.; SOTERO, Edilza; RIOS, Flavia. Coletivos negros e novas identidades raciais. Novos Estudos CEBRAP, v. 39, n. 2, pp. 309-327, 2020.

GUIMARÃES, Antonio Sérgio Alfredo. A recepção de Fanon no Brasil e a identidade negra. Novos Estudos, n. 81, pp. 99-114, 2008.

HANCHARD, Michel George. Orfeu e o poder. Rio de Janeiro: Ed. UERJ, 2001.

HASENBALG, Carlos A. Discriminação e desigualdades raciais no Brasil. Rio de Janeiro: Graal, 1979.

HOOKS, Bell. Ensinando a transgredir: a educação como prática da liberdade. São Paulo: Editora Martins Fontes, 2013.

HOOKS, Bell. O feminismo é para todo mundo: políticas arrebatadoras. Rio de Janeiro: Rosa dos Tempos, 2018.

HOOKS, Bell. Olhares Negros: raça e representação. São Paulo: Editora Elefante, 2019. HOOKS, Bell. Teoria feminista: da Margem ao Centro. São Paulo: Perspectiva, 2019.

IGREJA, Rebecca Lemos; AGUDELO, Carlos. Afrodescendentes na América Latina e Caribe: novos caminhos, novas perspectivas em um contexto global multicultural. Revista de Estudos e Pesquisas sobre as Américas, v. 8, n. 1, pp. 13-28, 2014.

JAMESON, Fredric. A virada cultural: reflexões sobre o pós-modernismo. Rio de Janeiro: Civilização Brasileira, 2006.

KILOMBA, Grada. Memórias da plantação: episódios de racismo cotidiano. Rio de Janeiro: Cobogó, 2019. 
LEITÃO, Leonardo Rafael Santos; SILVA, Marcelo Kunrath. Institucionalização e contestação: as lutas do Movimento Negro no Brasil (1970-1990). Política e Sociedade, v. 16, n. 37, pp. 315-347, 2017.

LOHN, Reinaldo Lindolfo. Reflexões sobre a história do tempo presente: uma história do vivido. In: REIS, Tiago Siqueira et al. (Orgs.). Coleção história do tempo presente. Volume I. Boa Vista: Editora da UFRR, 2019. pp. 11-26.

LOPES, Cristiano Aguiar. Pós-Graduação stricto sensu e produção científica no Brasil. Brasília: Câmara dos Deputados, 2019.

LORDE, Audre. Irmã Outsider: Ensaios e Conferências. Tradução de Stephanie Borges. São Paulo: Autêntica Editora, 2019.

MAHMOOD, Saba. Teoria feminista, agência e sujeito liberatório: algumas reflexões sobre o revivalismo islâmico no Egito. Etnográfica, v. 23, n. 1, pp. 135-175, 2019.

MAIO, Marcos Chor; SANTOS, Ricardo Ventura. Política de Cotas Raciais, os "olhos da sociedade" e os usos da Antropologia: o caso do Vestibular da Universidade de Brasília (UnB). Horizontes Antropológicos, ano 11, n. 23, pp. 181-214, 2005.

MATTOS, Bianca; SANTOS, Heloisa Helena de Oliveira; MATTOS, Suzana. Os estudos sobre mulheres negras no Brasil: levantamento quantitativo sobre o estado da arte das pesquisas sobre o tema no país. In: JOHAS, Bárbara; AMARAL, Marcela; MARINHO, Rossana (Orgs.). Violências e resistências: estudos de gênero, raça e sexualidade. Teresina: EDUFPI, 2020. pp. 181-201.

MIGNOLO, Walter D. Desobediência epistêmica: a opção descolonial e o significado de identidade em política. Tradução de Ângela Lopes Norte. Cadernos de Letras da UFF, Niterói, n. 34, pp. 287-324, 2008.

MOURA, Clóvis. Brasil: as Raízes do Protesto Negro. São Paulo: Global, 1983.

NASCIMENTO, Abdias do. Teatro Experimental do Negro: trajetória e reflexões. Estudos Avançados [online], v. 18, n. 50, pp. 209-224, 2004.

NASCIMENTO, Álvaro Pereira. Trabalhadores negros e "paradigma da ausência": contribuições à história social do trabalho no Brasil. Estudos Históricos, v. 29, n. 59, pp. 607-626, 2016.

NASCIMENTO, Maria Beatriz. Beatriz Nascimento, quilombola e intelectual: possibilidades nos dias de destruição. Diáspora Africana: Editora Filhos da África, 2018.

OTNER, Sherry B. Antropología y teoría social: Cultura, poder y agencia. Silvia Jawerbaum y Julieta Barba. Buenos Aires, Argentina: UNS, 2016.

PEREIRA, Amílcar Araújo. "O Mundo Negro": relações raciais e a constituição do movimento negro contemporâneo no Brasil. Rio de Janeiro: Pallas; FAPERJ, 2013. POULANTZAS, Nicos. O Estado, o poder, o socialismo. $3^{\text {a }}$ Ed. Rio de Janeiro: Graal. 1985.

RAMOS, Guerreiro. Introdução Crítica à Sociologia Brasileira. Rio de Janeiro: Editora UFRJ, 1995.

RICOEUR, Paul. Tempo e narrativa. Tomo I. Campinas: Papirus, 1994. 
SANTOS, Márcio André de O. dos. Política Negra e Democracia no Brasil Contemporâneo: reflexões sobre os movimentos negros. In: PAULA, Marilene de; HERINGER, Rosana (Orgs.). Caminhos convergentes: Estado e Sociedade na superação das desigualdades raciais no Brasil. Rio de Janeiro: Fundação Heinrich Böll; ActionAid Brasil, 2009a. pp. 227-258.

SANTOS, Sônia Beatriz dos. As ONGs de mulheres negras no Brasil. Sociedade e Cultura, v. 12, n. 2, pp. 275-288, 2009b.

SOUZA, Neusa Santos. Tornar-se negro, ou, as vicissitudes da identidade do negro brasileiro em ascensão social. 2. Ed. Rio de Janeiro: Graal, 1990.

TARROW, Sidney. Poder em movimento: movimentos sociais e confronto político. Petrópolis: Editora Vozes, 2009.

TELLES, Edward. Racismo à brasileira: uma nova perspectiva sociológica. Rio de Janeiro: Relume-Dumará; Fundação Ford, 2003.

TESTA, Mario. Pensamiento Estratégico y Lógica de Programación (El Caso de Salud). Buenos Aires: Lugar Editorial, 1995.

THOMPSON, E. P. A Formação da classe operária inglesa. Volume 3. $3^{\text {a }}$ Ed. Rio de Janeiro: Paz e Terra, 1987.

TRAPP, Rafael Petry; SILVA, Mozart Linhares da. Para além do Atlântico Negro: problematizações sobre antirracismo e transnacionalismo no Brasil (1978-2010). Oficina do Historiador, v. 5, n. 1, pp. 35-54, 2012.

VENTURINI, Anna Carolina; FERES JÚNIOR, João. Política de ação afirmativa na pós-graduação: o caso das universidades públicas, Cadernos de Pesquisa, v. 50, n. 177, 2020.

\section{NOTAS}

${ }^{1}$ III Conferência Mundial de Combate ao Racismo, organizada pela ONU em Durban, na África do Sul, em 2001.

${ }^{2}$ Para uma periodização do movimento negro no Brasil cf. Hanchard (2001), Domingues (2007) e Pereira (2013).

${ }^{3}$ Movimento surgido em 2013, que luta pela igualdade racial nos Estados Unidos.

Artigo submetido em 9 de maio de 2021.

Aprovado em 14 de julho de 2021.

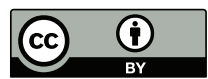

